\title{
DEGENERATION OF THE PAPILLO-MACULAR BUNDLE IN APES AND ITS SIGNIFICANCE IN HUMAN NEURO-PATHOLOGY
}

\author{
BY

\section{H. J. SCHERER} \\ From the Department of Pathology of the Institute Bunge and the Zoological Gardens \\ Antwerp, Belgium
}

(RECEIVED 19Th August, 1939)

\section{Introduction}

RothmanN (1906), Schröder (1908), and Schob (1931), published the early work on spontaneous lesions of the peripheral optic pathways in isolated cases of apes who died of a diffuse degenerative process in the white matter of the centrum ovale and (or) the spinal cord. These authors gave contradictory descriptions of the lesions in the optic pathways. Scherer (1932), who first recognized the pathological identity of this spontaneous disease in apes with that known in the human as "sub-acute combined degeneration" (Scherer, 1937) described these optic lesions in more detail. He emphasized their comparative frequency in this condition, and compared them to the rare optic nerve degenerations reported in human subacute combined degeneration. During recent systematic researches on the peripheral optic pathways in monkeys dying from a variety of causes, degenerative lesions in the optic nerves, chiasma, and tracts were found in a surprisingly high percentage of the animals, without degenerative changes elsewhere in the nervous system. Also, in these animals, the keepers had not noticed any visual disturbance during life.

The purpose of this paper is first to describe the frequency, exact localization, and histological characteristics of these lesions, and to discuss the possible pathogenesis. Secondly, to compare these lesions with corresponding changes occurring in man and also with those in monkeys affected by definite degenerative changes in other parts of the nervous system (subacute combined degeneration).

\section{Material and Methods}

For the purpose of this work post-mortem examinations have been made on 27 apes, the majority of which were cercopithecidæ (Macacus Rhesus, different types of cercopithecus, cercocebus, etc.). In all cases, both optic tracts and the chiasma were examined by means of coronal sections which cut the nerve fibres in a somewhat longitudinal direction. In 13 of the cases the 
intra-orbital portions of both optic nerves were examined by longitudinal and cross section. Frozen sections were stained with Scharlach Red for fatty degenerative products, by the Spielmeyer method for myelin sheaths, and with Cresyl Violet. In those stained for myelin, the commencement of the lesion was often difficult to detect, but the Scharlach Red and Nissl preparations showed even very slight changes. In the myelin stained preparations, artefacts may easily simulate degenerative changes, therefore only those preparations in which degeneration was confirmed by the Scharlach Red and Nissl stains, are quoted. Besides these 27 cases, 5 cases of pure optic degeneration, and the optic lesions in 15 apes with encephalo-myelosis, all observed before we began this research, have been carefully re-studied.

\section{Results}

Systematic Study.-In 19 of the 27 cases in which the peripheral optic pathways were examined no lesion was found. The remaining 8 had definite changes, always symmetrical, either in the optic tracts alone, or in the whole peripheral optic system. In none of these 27 cases could we find other degenerative changes in the white matter of either the central or peripheral nervous system. The optic lesions in these cases had never a focal, but always a fascicular and symmetrical character. However, there were definite differences from case to case in the intensity and extent of the degenerative lesions. These differences and the character of the lesions were as follows :

The initial lesion occurred in the upper postero-lateral field of the optic tract, and extended down from there to the central, and forwards to the under medial parts (Fig. 1). The lesion was always confined to a sharply limited bundle of

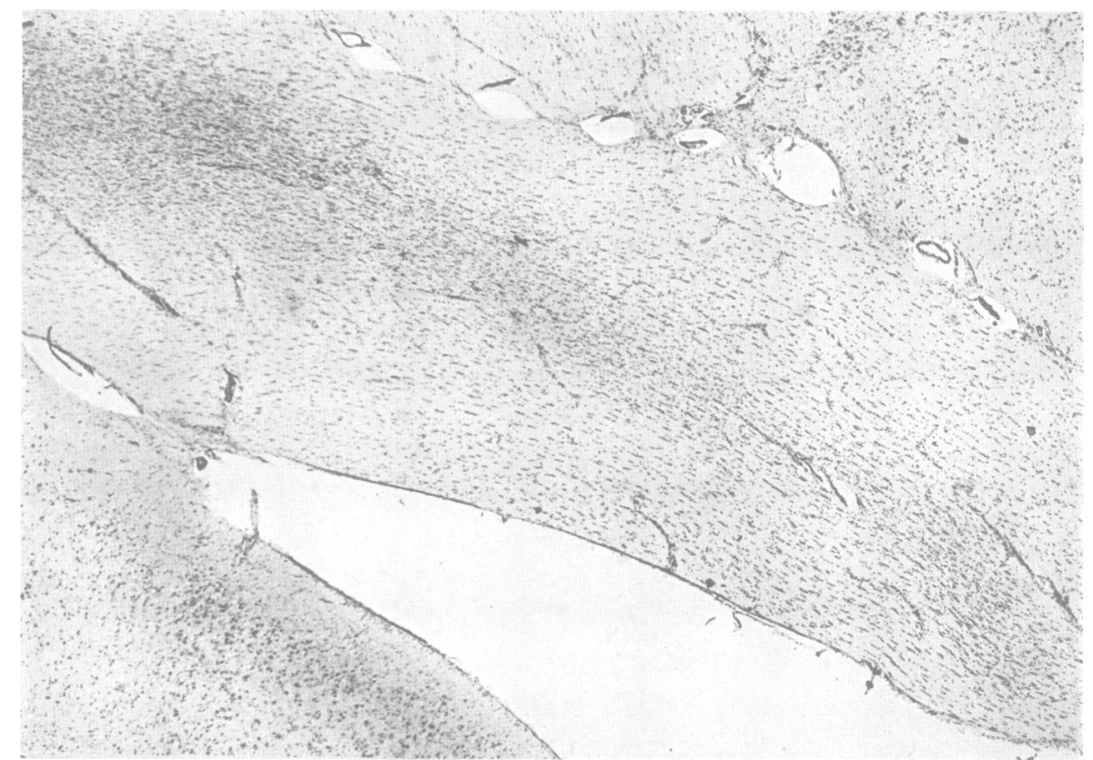

Fig. 1.-Optic tract, coronal section, Nissl stain. The degenerated field, recognizable by the multiplication of glial nuclei, goes from the upper lateral parts (upper left corner) to the lower medial parts of the tract (lower right corner). Same case as Fig. 2. 
fibres. In the anterior half of the chiasma (Fig. 2) cross sections generally howed an extensive degeneration of the central parts, while a small portion of the fibres at the dorsal and ventral edge remained intact. The posterior half of the chiasma showed no degeneration.

At this stage the myelin stain showed no lesion, but with fat stains there was

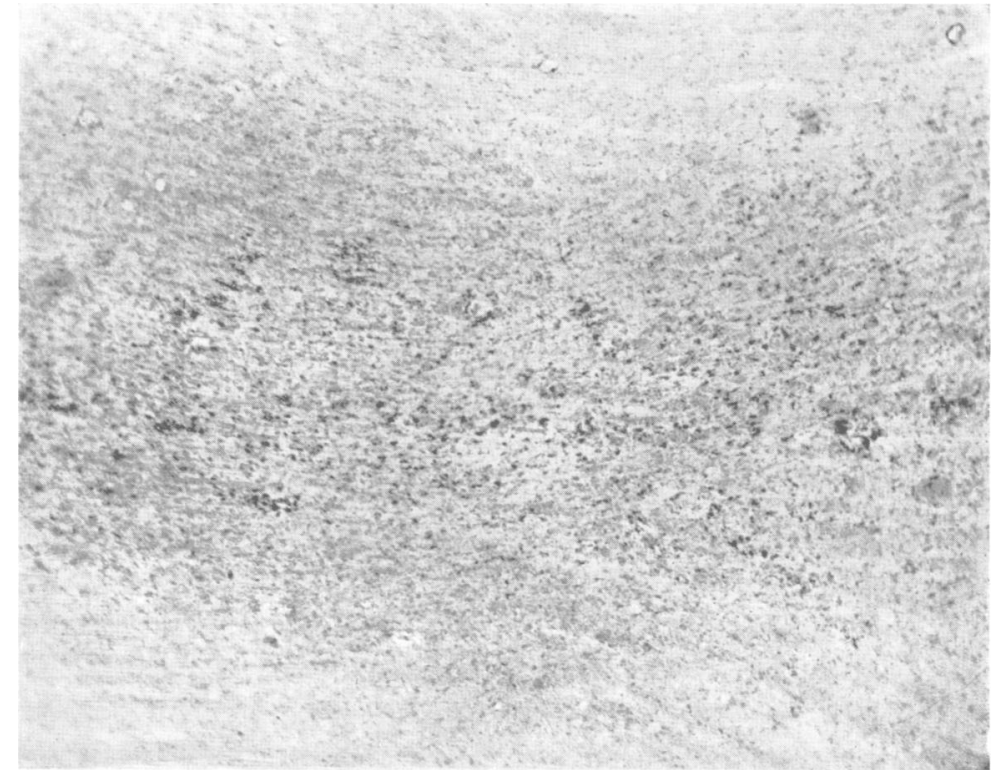

Fig. 2.-Anterior half of chiasma, coronal section, Scharlach red stain. The fat substances (black in the picture) are situated in a central location.

a definite fatty degeneration, and with nuclear stains a fairly pronounced multiplication of the glial nuclei (Fig. 1), limited exactly to the same field as the Scharlach Red coloured substances. These substances were evenly distributed in fixed glial elements (Fig. 5), and there were no compound granular cells. The intraorbital portion of the optic nerves in only one such case failed to show any lesion.

At the next stage, the lesion in the optic tracts showed exactly the same localization and extent, but the fatty degeneration had become more intense, and there was a commencing alteration in the myelin picture. However, the degeneration conserved the "fixed" type, and compound granular cells remained rare. In these cases, however, the intraorbital optic nerves showed definite lesions, and always in the same location. Cross sections of the optic nerve immediately behind the eye bulb showed a rather triangular field of degeneration whose apex coincided with the central vessels, and whose base was formed by the lateral surface of the nerve (Fig. 3,a). Posteriorly, where the central vessels had left their central position and approached the periphery, the degeneration covered a superficial field of semilunar shape, whose convex side coincided with the lateral surface of the nerve, while the concave side had a tendency to retract itself away from the central vessels (Fig. 3, b, 4). More 
posteriorly, where the central vessels had left the nerve, the field had a rounder shape and retracted itself more and more from the surface (Fig. 3, c), becoming central in position in the most posterior part of the intraorbital segment of the nerve.

The limitation of the degenerated field was always sharply outlined and there was no doubt about the definite fascicular character of this degeneration
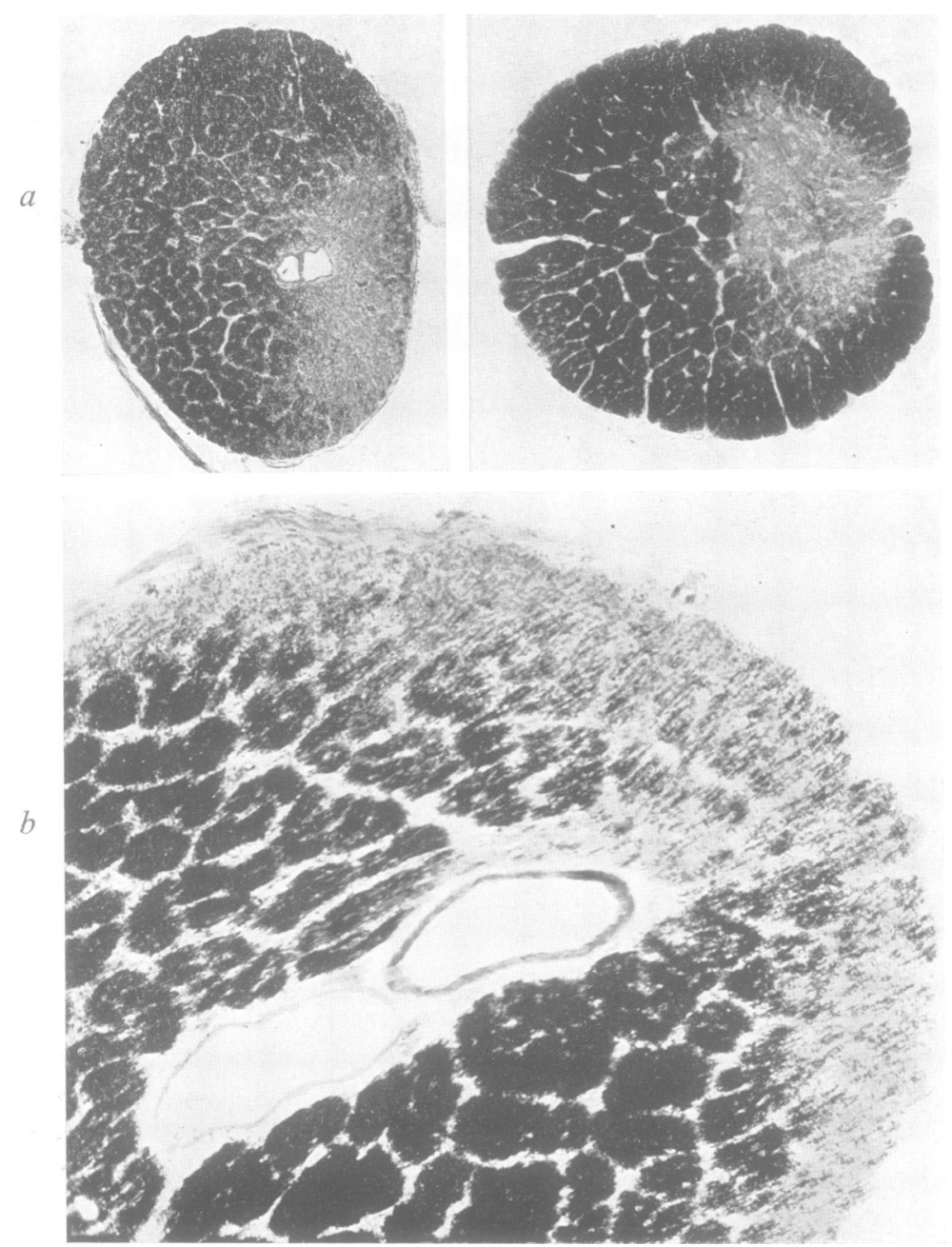

Fig. 3.-Cross-sections through the anterior $(a)$ mid- $(b)$ and posterior $(c)$ parts of the intraorbital portion of the optic nerve. Spielmeyer stain for myelin. $(a)$ and $(c)$ same low magnification (b) higher magnification.

both in transverse and longitudinal sections. The histological character of the lesions was the same as described above for the optic tracts : first, a slight fatty degeneration with the appearance of the fat substance in the fixed glial elements and in mesenchymal cells of the connective tissue of the nerve (Fig. 4) and a 
definite increase of glial nuclei in Nissl pictures. Second, a clear loss of myelin appeared in the same localization, while, with the intensification of the disintegration compound granular cells appeared, these generally not being very numerous. However, even in these advanced cases, the demyelinization of the affected areas was never complete, a considerable number of the myelin fibres always remained intact (Fig. 3, b).

Finally, and only in rare cases, a more diffuse degeneration was observed in

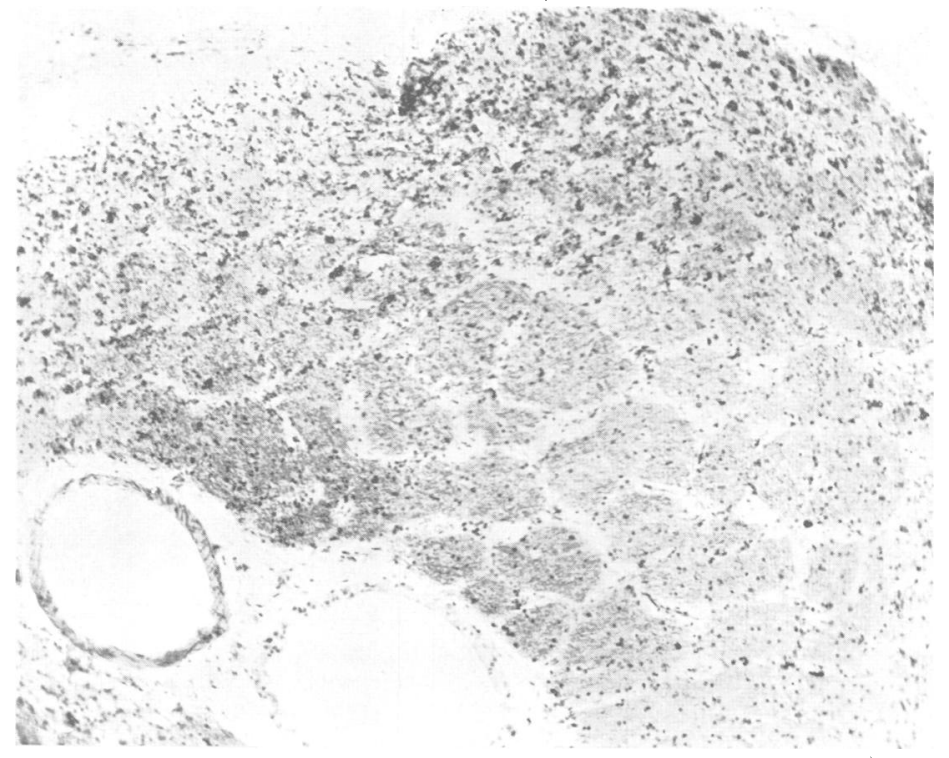

Fig. 4.-Cross-section through the intraorbital portion of optic nerve immediately before central vessels leave the nerve: Scharlach red stain. Degeneration limited to the characteristic peripheral field (same case as Fig. 5).

the optic tracts and chiasma, covering practically the whole cross section of these structures, and no longer confined to the circumscribed bundle described above. But in one of these cases, in the intraorbital part of the optic nerves, a definite fascicular degeneration of a circumscribed fibre bundle was observed, whose location corresponded exactly to that of the optic nerve lesions in early cases. The character of the degeneration remained the same as in earlier stages, even in the optic tracts : fat globules, usually in the fixed glial elements, the arrangement of which was quite regular and followed uniformly the direction of the fibres (Fig. 5).

Isolated Optic Degeneration observed outside this Study.-The collections in our laboratory contained 5 other cases of monkeys, 2 of which have been published later in detail by Dr. Van Bogaert, with identical optic degenerations but without other white matter lesions. These had been observed before beginning our systematic researches. In 2 of these cases there were clinical symptoms of cecity, and the lesions were especially pronounced. In 1 case, the optic tract lesion was so severe that there was 
already a zone of real softening. Unfortunately, only tracts and chiasma had been examined in all these cases, but in three cases at least, the localization and character of the optic tract lesions were the same as in the cases described above.

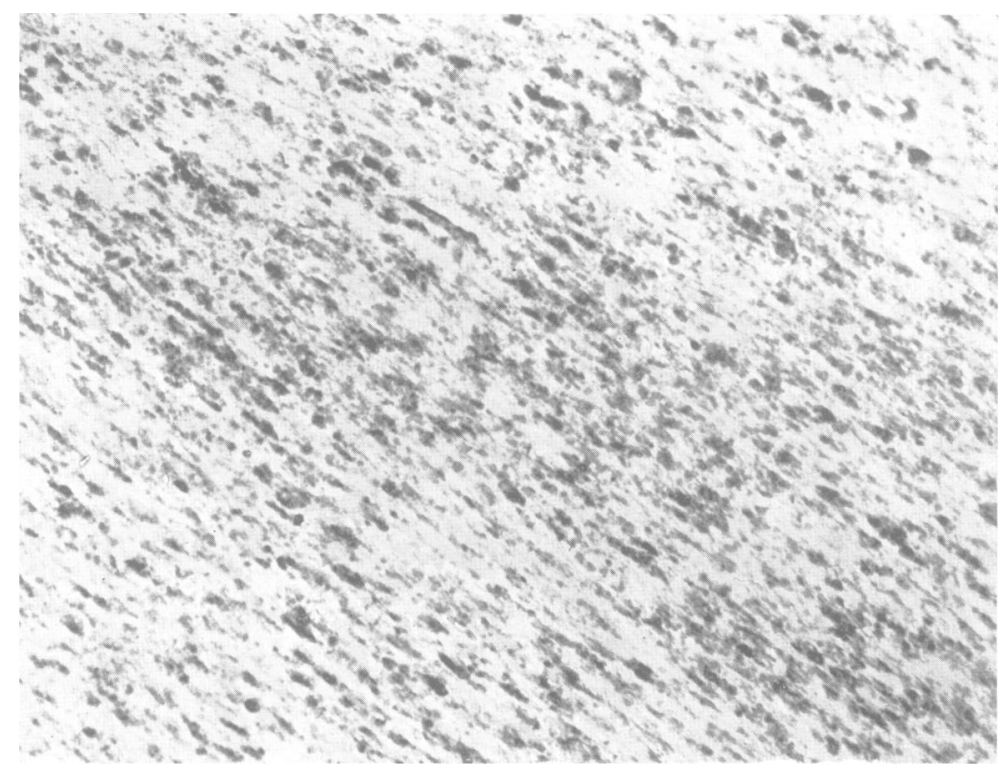

Fig. 5.-Coronal section through the optic tract of the same case as Fig. 6, Scharlach red stain. The optic tract shows diffuse degeneration. Degeneration products evenly distributed in fixed glial elements following the fibre direction. Compare with Fig. 8.

Character of Optic Degeneration in Cases of Encephalo-Myelosis.-The optic nerve lesions in apes with encephalo-myelosis (subacute combined degeneration) were re-examined after this systematic study. These lesions were described (Scherer, 1932) as a systemic degeneration of a fibre bundle in the upper postero-lateral part of the optic tracts (Fig. 6). This location corresponded exactly to that of the optic lesions described in this paper. As, in one of these cases, multiple focal lesions were seen in the anterior part of the optic tract, and as the anterior parts of the optic nerves from the other cases were not available, this fibre bundle lesion was considered to be probably a secondary degeneration caused by focal lesions elsewhere. These lesions on being restudied, were without doubt due to a primary systemic degeneration of the bundle concerned, which might, in rare cases, be accompanied by focal lesions in the peripheral optic system, identical to the patches found in the spinal cord or centrum ovale. This conviction was based on evidence that in cases of encephalo-myelosis there occurred an undoubted degeneration of the same bundle, and also in the intraorbital part of the optic nerve, but unaccompanied by focal lesions in this part.

Fig. 7 shows the optic tracts and chiasma of such a case : the centrum ovale had the typical lesions of encephalosis, the intraorbital part of the nerve showed a typical, but quite advanced degeneration of the same bundle, without any 
focal lesion. In the chiasma and optic tract a large fascicular zone of demyelinization was seen ; at the same time, a considerable number of newer and older patches of demyelinization were seen, some of which were confluent with
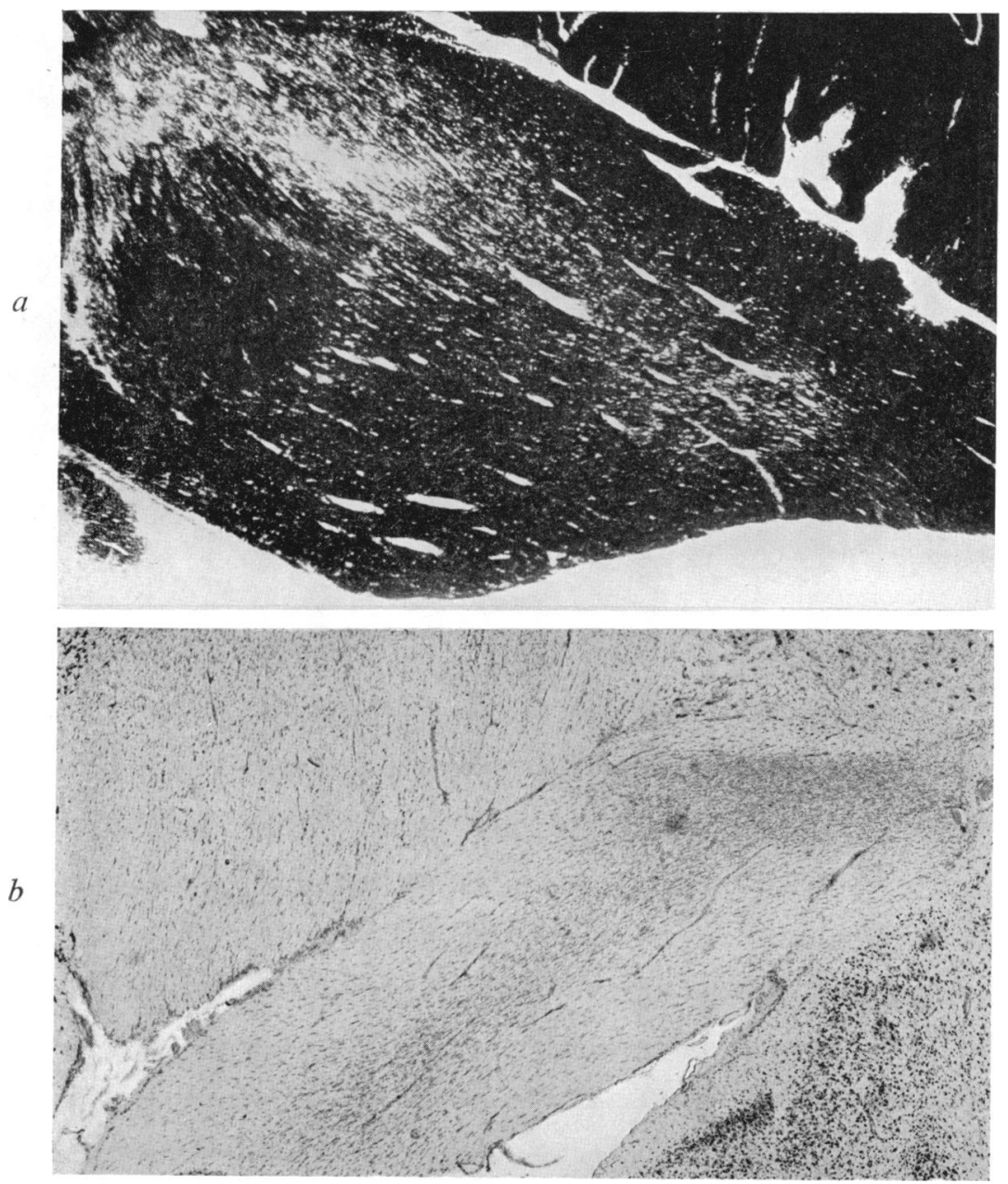

Fig. 6.-Optic tract from a case of commencing subacute combined degeneration of the spinal cord. (a) Most posterior part of the tract, myelin stain : degeneration of the lateral upper corner ; (b) More anterior part of the tract, Nissl stain : the degenerated field goes down from the upper lateral corner to the under medial parts. Compare with Fig. 1.

the degenerated fascicles. Fat stains showed the definite focal character of the disintegration (Fig. 8), and there was a predominance of " mobile" disintegration with numerous compound granular cells in these patches.

General Disease in Affected Cases.-From the 13 cases of isolated optic degeneration, 4 died from generalized tuberculosis, 2 from mild chronic lymphocytic meningitis, 3 from a general cachexia after clinical gastrointestinal disturbances but without definite pathological lesions. In the 
others the cause of death was not evident. Amongst the cases of encephalo-myelosis with optic degeneration, there were 3 with definite
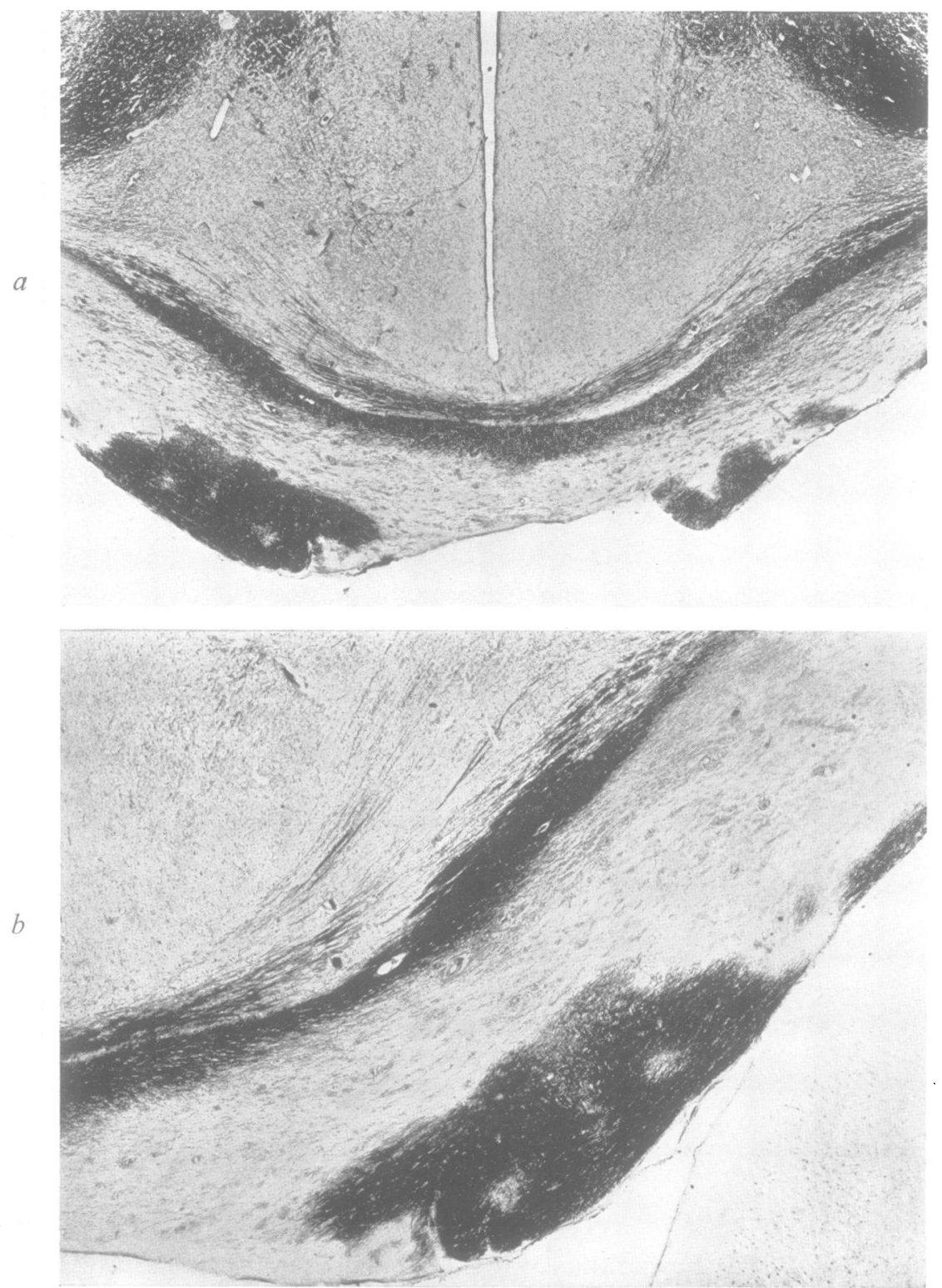

Fig. 7.-Systemic bundle degeneration and multiple focal lesions in chiasma and optic tracts of a case of encephalosis (cerebral form of subacute combined degeneration) Spielmeyer's stain. (a) General view, (b) detailed picture.

chronic colitis, 1 with generalized tuberculosis. Several of our old cases, and cases from the literature showed the occurrence of gastro-intestinal troubles. There was, however, no constant correlation : controls of the 
optic pathways in numerous monkeys who died from generalized tuberculosis and severe chronic colitis showed that in spite of these conditions the optic pathways might be perfectly normal. But, although the gastro-intestinal tract

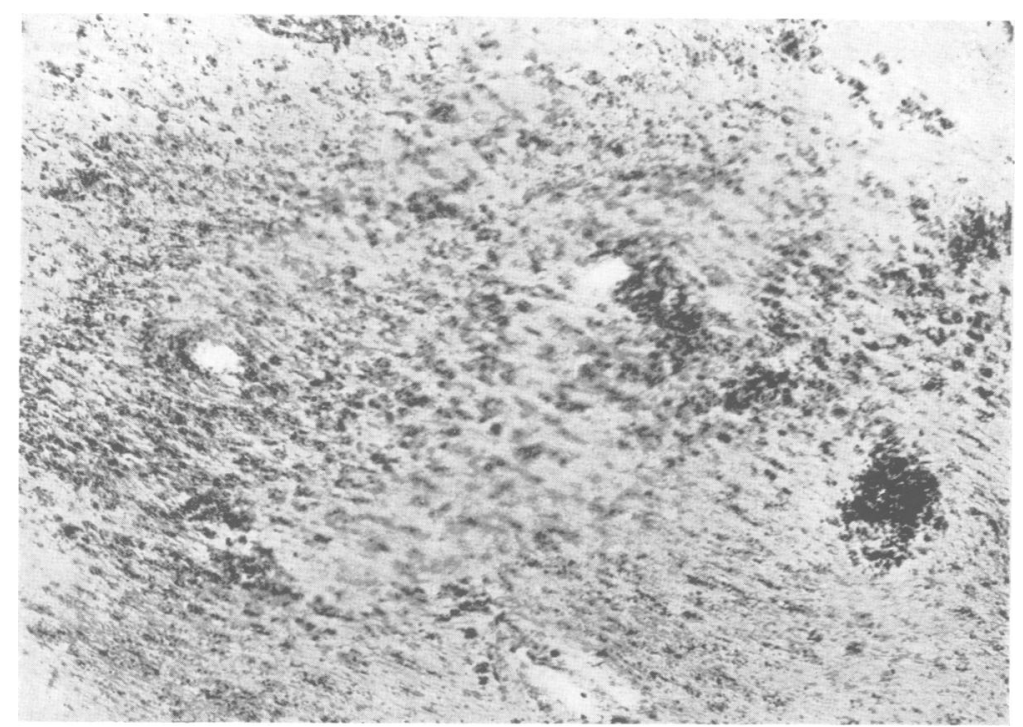

Fig. 8.-Scharlach red detail picture from one of the chiasma patches of Fig. 7. Note the focal character of lesions, the concentration of granular compound bodies around the vessels. Compare with Fig. 5.

in our earlier cases had not been examined carefully enough, there seemed to be an astonishing frequency of primary, or secondary (in generalized tuberculosis) gastro-intestinal troubles in cases of subacute combined degeneration as well as isolated lesions of the papillo-macular bundle.

\section{Comment}

We may say, therefore, that isolated symmetrical bundle degenera tions in the optic nerves and tracts are frequent in captive monkeys which show no other lesions of the nervous parenchyma. In most cases they are so recent that a definite myelin loss is not readily recognized, but only a commencing fatty degeneration strictly confined to a definite fibre bundle. In other words, this seems to occur, in most cases, only a few days before death. The causes of death were, generalized tuberculosis, slight lymphocytic meningitis, and gastrointestinal disturbances; sometimes the necropsy revealed no clear cause of death. The degeneration seems to begin in the optic tract and to involve the optic nerves later. The lesions in the former are frequently more intense than those in the latter, and in one case with a very recent lesion in the tracts, the intraorbital part of the optic nerves did not show any lesion at all. However, this point still needs further study. The first question to ask is, what kind of fibres show this pronounced vulnerability? and the second, what is the ætiology of this curious process? 
The constancy of location presented by this lesion in all positive cases, as well as in different parts of the peripheral optic pathways, seems to suggest that it is due to degeneration of a definite fibre unit. The location of this fibre unit corresponds to that of the papillo-macular bundle in man, as given in the schema of Uthoff-Abelsdorff. Furthermore, the finer histological characters (scarcity of compound granular cells, incomplete demyelinization, etc.), are the same as described in papillo-macular bundle degeneration in the human (see Abelsdorff, 1928). There is present, therefore, in all these monkeys, a systemic degeneration of the papillo-macular bundle, and it is only in very advanced cases that the degeneration affects the whole of the optic tracts. With regard to the cases where this bundle degeneration is part of subacute combined degeneration in monkeys, we wish to draw attention to the fact that optic atrophy in human subacute combined degeneration has been observed by Bielschowsky (1901), Ungley and Suzman (1929), Ossenkopp (1931), Courville and Nielsen (1938), Rothfeld (1938), and others. Unfortunately careful study of such optic lesions in man are still lacking.

The problem of the ætiology is more difficult to answer. It is certain that the affected animals died from quite different diseases and all of which certainly had a much longer duration than the degeneration of the papillo-macular bundle. As this degeneration seems to be frequently a terminal complication the possibility of an alimentary deficiency has to be considered as a cause.

Let us consider here $(a)$ the degeneration of the papillo-macular bundle in man, and $(b)$ the degeneration in the same bundle in apes with lesions of the white matter of the type of "subacute combined degeneration" (encephalomyelosis).

(a) The sole fact recognized in the human papillo-macular degeneration (" neuritis retrobulbaris "), is that its ætiology may differ greatly. The most frequent causes seem to be poisoning by alcohol, or nicotine, and the diseases diabetes mellitus, hyperemesis gravidarum, etc., that is to say the same conditions that frequently cause peripheral nerve degeneration. These peripheral " neuritides" are actually considered to be due to secondary B avitiminosis following on the primary intoxication or metabolic disorder. Cases of retrobulbar neuritis have also been observed (quoted after Schieck, 1938) in pellagra, beri-beri, carcinomatous cachexia and by generally insufficient nutrition (Moore, 1934). The hypothesis that a mechanism similar to that acting in peripheral neuritis may be responsible also for the degeneration of the papillo-macular bundle needs careful consideration, and has been discussed recently in some ophthalmological papers (Yudkin, 1933 ; Carroll, 1937 ; Paternostro, 1938 ; and others) but without definite conclusion.

(b) The fact that an identical degeneration of the papillo-macular bundle is one of the most constant features to be observed in subacute combined degeneration in monkeys (in the spinal as well as the cerebral forms) speaks again in favour of an avitaminosis or at least a deficiency as the origin of this bundle degeneration when it occurs as an isolated lesion. Since my first publication about subacute combined degeneration in monkeys, I have emphasized the possibility of its being due to an avitaminosis. All that we have learned about this condition 
since favours this theory more and more.* The researches of Hamerton (1938) seem especially to favour this theory. Also, certain observations on human subacute combined degeneration seem to favour the same hypothesis (Schlesinger, 1920 ; Modes, 1922, et al.). Furthermore, from the work of Gildea, Kattwinkel and Castle (1930), of Zimmerman and his co-workers (1933, 1936, 1937) and others, it is known that avitaminosis (of A as well as B2), is able to provoke in dogs and rats, not only peripheral nerve lesions but also degenerative lesions in the white matter of the spinal cord. Although these lesions, as far as the description allows of judgement, do not seem to be identical with those of subacute combined in man and apes, they prove, in principle, that deficiency can affect the white matter of the central nervous system.

These facts are, of course, no proof of the deficiency nature of the papillomacular bundle degeneration, but they are certainly sufficient to admit it as a working hypothesis for further investigation. They would justify the attempt to produce, by systematic avitaminosis experiments, not only papillo-macular bundle degeneration but the lesions of subacute combined degeneration in apes. Up to now, avitaminosis experiments have been carried out largely with dogs and rats, animals in which spontaneous optic nerve lesions or subacute combined degeneration were unknown until now. It seems logical to try the experimental realization of these conditions in an animal which shows such a definite tendency to their spontaneous appearance, as the ape.

\section{Summary}

A spontaneous systemic degeneration of the papillo-macular bundle is frequently found in captive monkeys dying from different general diseases. In routine optic nerve examinations it has been observed in 8 out of 27 cases, most of these were of recent onset.

The optic nerve lesions which accompany most cases of spontaneous "encephalosis" and "myelosis" in monkeys (cerebral and spinal form of subacute combined degeneration), are also systemic degenerations of the papillomacular bundle. They may be complicated by the appearance in the peripheral optic pathways of the same circumscribed, later confluent, patches of demyelinization which characterize the disease in the spinal cord and centrum ovale.

The frequency of the optic lesion and its often terminal character in different general diseases (generalized tuberculosis, gastro-intestinal troubles, cachexia, meningitis, etc.) suggests that its origin may be in a nutritional deficiency, and that this may also account for the lesions of subacute combined in monkeys.

* In a short abstract of a verbal communication Gärtner $(1932,1933)$, published a successful transmission of the condition in 8 cases by intracerebral or intramuscular inoculation of brain tissue and cerebrospinal fluid from affected cases. Unfortunately these researches have never been published in detail, and it is impossible to be sure of the following points : 1 , whether the author was really dealing with the same affection or not. 2, whether an avitaminosis was excluded in his experiments or not. As he does not speak of controls there would be no proof that the inoculation caused the condition, it might have been caused by a coincidental deficiency in all these monkeys. Gärtner even mentions gastro-intestinal troubles and pathological lesions of the digestive tract in his cases, so that this communication gives no adequate evidence for an infectious cause of subacute combined degeneration in monkeys. 
Our actual knowledge of human papillo-macular bundle degeneration seems to support this hypothesis.

I am indebted to M. L'Hoëst, Director, Dr. Collet, Veterinary, and M. De Vooght, Department Chief, of the Zoological Gardens, Antwerp, for their help which enabled me to obtain the material for these researches.

\section{REFERENCES}

Abelsdorff, G. (1928). Henke-Lubarsch Handbuch Path. Anat., 11, 695.

Bielschowsky, M. (1901). Myelitis und Sehnervenentzündung, Berlin, Karger.

Bogaert, L. van (1939). Ann. Inst. Pasteur. 63, 315.

Carroll, F. D. (1937). Arch. Ophthal., 18, 948.

Courville, C. B., and Nielsen, J. M. (1938). Bull. Los Angeles Neurol. Soc., 3, 83.

Gärtner, W. (1932). Klin. Wschr., 11, 905. (1933). Arch. Psychiat., 99, 822.

Gildea, E. F., Kattwinkel, E. E., and Castle, W. B. (1930). New England J. Med., 202, 523. Hamerton, E. (1938). Proc. zool. Soc. London, Series B, 108, 512.

Modes, U. (1922). Z. ges. Neurol. Psychiat., 78, 291.

Moore, D. G. F. (1934). Ann. trop. Med., 28, 295. (Quoted after Schieck.)

Ossenkopp, G. (1931). Dtsch. Z. Nervenheilk., 117, 350.

Paternostro, O. (1938). Ann. Ottalmol., 66, 891.

Rothfeld, J. (1938). Confinia Neurologica, 1, 243.

Rothmann, A. (1906). Mschr. Psychiat. Neurol., 20, 204.

Scherer, H. J. (1932). Z. ges. Neurol. Psychiat., 141, 212.

- (1937). Rev. Neurol., 68, 807.

Schieck, F. (1938). Zbl. Ophthal., 41, 193.

Schlesinger, H. (1920). Z. ges. Neurol. Psychiat., 59, 1.

Schob, F. (1931). Ibid., 135, 95.

Schröder, P. (1908). Arch. Psychiat., 44, 193.

Ungley, C. C., and Suzman, M. M. (1929). Brain, 52, 271.

Yudkin, A. M. (1933). J. Amer. med. Ass., 101, 921.

Zimmerman, H. M. (1933). J. exp. Med., 57, 215.

Zimmerman, H. M., and Cowgill, G. R. (1936). J. Nutrit., 11, 411.

Zimmerman, H. M., Cowgill, G. R., and Fox, J. C. (1937). Arch. Neurol. Psychiat., Chicago, 37, 286. 